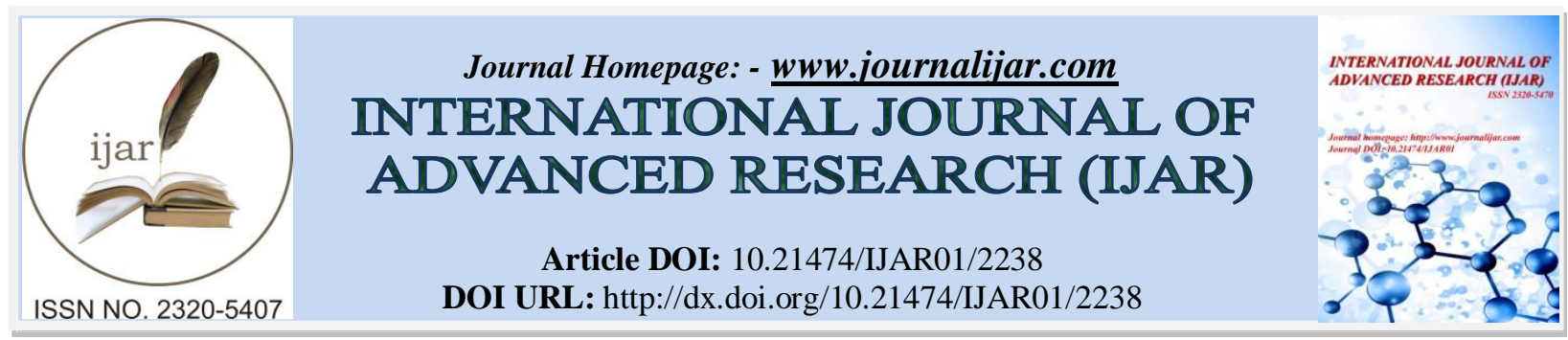

RESEARCH ARTICLE

\title{
COMPLIANCE OF SAUDI DIABETIC PATIENTS WITH THEIR DIABETIC MEDICATION.
}

\author{
"Muthbat Ayidh Muthbat Al Dawsari, Mohammed Abdulaziz Al Qauyyed, Mubarak Ali Al-Dawsari, Nasser \\ Mathyab Al-boqami, Abdulrahman Rayi Alruwaili, Abdulaziz Khaled Alareefy, Ibrahim Mohsen \\ Mutawwam and Ahmed Mohsen Ahmed Mutawwam.
}

Interns, Faculty of Medicine, Imam Mohammad University, Riyadh, Saudi Arabia.

\section{Manuscript Info}

Manuscript History

Received: 29 September 2016

Final Accepted: 30 October 2016

Published: November 2016

Key words:-

Compliance; anti-diabetics;

determinants; Diabetes; online

\section{Abstract}

Background: In recent years there were a lot of studies showing increasing numbers of complication in diabetic patient in the world include Saudi population. Amongst the most important reasons for such complications is the non-adherence of diabetic patient with their medication, diet and exercise.

Objectives: To explore the rate and determinants of non-compliance with diabetic treatment regimen in Saudi Arabia population.

Subjects and methods: A cross-sectional study was conducted among Saudi diabetic patients. Online approach was adopted to enroll patients through filling the study questionnaire throughout the period between 1 st to 30 October, 2016. Inclusion criteria were Saudi, diabetic and have online access patients. Our outcomes were compliance with anti diabetic medication and the associated factors. An online pretested semi-structured questionnaire was utilized for date collection.

Results: The study included 1473 Saudi diabetic patients. The age of $31.4 \%$ of them ranged between 41 and 60 years. Slightly more than half of them $(54.1 \%)$ were males, married $(52.2 \%)$, university educated (50.9\%) and $60.1 \%$ of them were type 2 diabetic patients. Compliance with physicians` visits was reported by majority of them (80.2\%). However, this compliance was perfect among $42.5 \%$ of patients. Glycated hemoglobin percentage exceeded $8 \%$ among $33.7 \%$ of patients. Minority of patients $(8.7 \%)$ reported difficulty in getting antidiabetic drugs. Using traditional medicine in treating diabetes was reported by $14.7 \%$ of the participants; however it was a lot among $2.3 \%$ of them. Daily compliance with diabetic drugs was reported among $60.3 \%$ of the patients. The commonest reported reasons for escaping a daily dose of anti-diabetic drugs were being not definitely explained by physician $(52.7 \%)$ and forgetting (21.7\%). Most of the participants reported being reminded by family members to have the drugs. The most frequent reported sources of patient`s information regarding diabetes were physicians (69.6\%) and internet (59.9\%). The determinants of none-compliance to anti-diabetic medications were young age, younger age at diagnosis, moderate educational level, type 2 diabetes, absence of co-morbid diseases, never compliance with physicians visits, treatment by anti-diabetics, use of traditional medicine and having information about diabetes from the family. 
Conclusion: Rate of non-compliance with anti-diabetic medication among Saudi diabetes is high and significantly associated with personal and diabetes-factors.

Copy Right, IJAR, 2016,. All rights reserved.

\section{Introduction:-}

Diabetes is a chronic disease that occurs either when the pancreas does not produce enough insulin or when the body cannot effectively use the insulin it produces. ${ }^{1}$ The prevalence of type 2 diabetes mellitus is increasing globally and has become a major public health problem. ${ }^{2}$ In 2012, diabetes was the direct cause of 1.5 million deaths and in 2014 , $9 \%$ of adults 18 years and older had diabetes. ${ }^{1}$

More than $80 \%$ of diabetes deaths occur in developing countries. ${ }^{3}$ In Saudi Arabia, among patients attending a primary care clinic diabetes mellitus was present in $30 \%{ }^{4}$ The rate of non-compliance in patients with chronic diseases in developed countries, on long-term treatment, is on the order of $50 \%$. This could be even higher in developing countries (WHO-2010). ${ }^{5}$ For example, in India, a study showed patient-reported adherence rates for medication in type 1 and type 2 diabetic patients of 83 and 78\%, respectively; self monitoring blood glucose (SMBG) adherence was 70 and 64\%, respectively; and appointment keeping adherence was 71 and $72 \%$, respectively. The adherence rates observed for diet for type 1 and type 2 diabetic patients were 39 and $37 \%$, respectively, and for exercise they were 37 and $35 \%$, respectively. ${ }^{6}$

Non-compliance can be due to factors that are patient-centered, therapy-related, or healthcare system-related. The patient-centered factors can be demographic (age, gender, educational level, and marital status) and psychological (patients' beliefs and motivation towards the therapy, negative attitude, patient-prescriber relationship, understanding of health issues, and patient's knowledge). The therapy-related factors include route of medication, duration of treatment, complexity of treatment, and the side effects of the medicines. The factors associated with the healthcare system include availability, accessibility, and the physician. ${ }^{6}$

In recent years there were a lot of studies showing increasing numbers of complication in diabetic patient in the world include Saudi population. ${ }^{7-9}$ Amongst the most important reasons for such complications is the non-adherence of diabetic patient with their medication, diet and exercise. Therefore, this study aimed to explore the rate and determinants of non-compliance with diabetic treatment regimen in our community in Saudi Arabia population.

\section{Subjects and methods:-}

A cross-sectional study was conducted among Saudi diabetic patients. Online approach was adopted to enroll patients through filling the study questionnaire throughout the period between 1 st to 30 October, 2016. Inclusion criteria were Saudi, diabetic and have online access patients. We excluded those who were newly diagnosed with diabetes (less than one month) from the study. Our outcomes were compliance with anti diabetic medication and the associated factors.

Sample size of the current study was calculated assuming that the number of diabetics in Saudi Arabia is 3487000 in $2015,{ }^{10} 70 \%$ of diabetic patients are not compliant with any self-management approach. ${ }^{11-13}$ At $99 \%$ confidence interval and 3\% worst acceptable limit, the estimated sample size was 1547 using Epi-Info version, 7.

An online pretested semi-structured questionnaire was utilized for date collection. It was adopted from that used in a similar study carried out in Uganda. ${ }^{14}$ It collected information regarding demographic characteristics of patients (age, gender, marital status and educational level), diabetes-related characteristics (type of diabetes, age at diagnosis, co-morbid diseases, compliance with physicians` visits, last $\mathrm{HbA}_{1} \mathrm{c}$ level, difficulty in getting anti-diabetic drugs, diabetic therapy, side effects of anti-diabetic drugs, source of information regarding diabetes, using traditional medicine in treating diabetes, non-compliance with anti-diabetic daily dose and remaining system used to have antidiabetic medication.

Therapeutic compliance means that the patient observes the medical recommendations, taking the medication, and maintaining a lifestyle as recommended by clinicians. ${ }^{15,}{ }^{16}$ In this study, Focus on medication compliance was considered. Compliance with diabetic medication was determined through self-reports of how patients had escape 
daily dose in a month. In the present study, we considered patients who missed drugs for one day at least in the moth as non-compliant with anti diabetic drugs.

Approval of the regional research and ethics committee, Riyadh was obtained. Data were collected and analyzed using SPSS version 22. Descriptive statistics such as number, percent, means, median and standard deviation as well as analytic statistics such as chi-square tests were applied. Significance was determined at $p$ value $\leq 0.05$.

\section{Results:-}

The study included 1473 Saudi diabetic patients. The age of 31.4\% of them ranged between 41 and 60 years. Slightly more than half of them (54.1\%) were males, married (52.2\%) and university educated (50.9\%).Table 1

Table 1:- Demographic characteristics of the participants $(\mathrm{n}=1473)$

\begin{tabular}{|l|l|l|}
\hline & Frequency & Percentage \\
\hline Age in years & & \\
$<18$ & 204 & 13.8 \\
$18-25$ & 376 & 25.5 \\
$26-40$ & 315 & 21.5 \\
$41-60$ & 463 & 31.4 \\
$>60$ & 115 & 7.8 \\
\hline Gender & & \\
Male & 797 & 54.1 \\
Female & 676 & 45.9 \\
\hline Marital status & & \\
Married & 768 & 52.2 \\
Single & 634 & 43.0 \\
Widowed & 44 & 3.0 \\
Divorced & 27 & 1.8 \\
\hline Educational level & & \\
Illiterate & 93 & 6.3 \\
Primary school & 168 & 11.4 \\
Intermediate school & 115 & 7.8 \\
Secondary school & 348 & 23.6 \\
University & 749 & 50.9 \\
\hline
\end{tabular}

From table 2, it is shown that $60.1 \%$ of them were type 2 diabetic patients. Age at diagnosis was less than 18 years among $36.4 \%$ of them and ranged between 26 and 40 years among $27.1 \%$ of patients. Co-morbid diseases were reported among $38.6 \%$ of them; mainly hypercholesterolemia (18.9\%) and hypertension (11.1\%). Compliance with physicians` visits was reported by majority of them (80.2\%). However, this compliance was perfect among $42.5 \%$ of patients. Glycated hemoglobin percentage exceeded $8 \%$ among $33.7 \%$ of patients. Minority of patients (8.7\%) reported difficulty in getting anti-diabetic drugs. Insulin was taken by $56.3 \%$ of patients whereas regulator and antidiabetics were reported by $29.1 \%$ and $12.6 \%$ of patients. Almost one-fifth of patients (20.9\%) reported side effects of anti-diabetic drugs. Using traditional medicine in treating diabetes was reported by $14.7 \%$ of the participants; however it was a lot among $2.3 \%$ of them. Daily complaiance with diabetic drugs was reported among $60.3 \%$ of the patients.

Table 2:- Diabetes-related characteristics of the participants

\begin{tabular}{|l|l|l|}
\hline & Frequency & Percentage \\
\hline Type of diabetes & & \\
Type 1 & 587 & 39.9 \\
Type 2 & 886 & 60.1 \\
\hline Age at diagnosis & & \\
$<18$ & 536 & 36.4 \\
$18-25$ & 205 & 13.9 \\
$26-40$ & 399 & 27.1 \\
$41-60$ & 313 & 21.2 \\
$>60$ & 20 & 1.4 \\
\hline
\end{tabular}




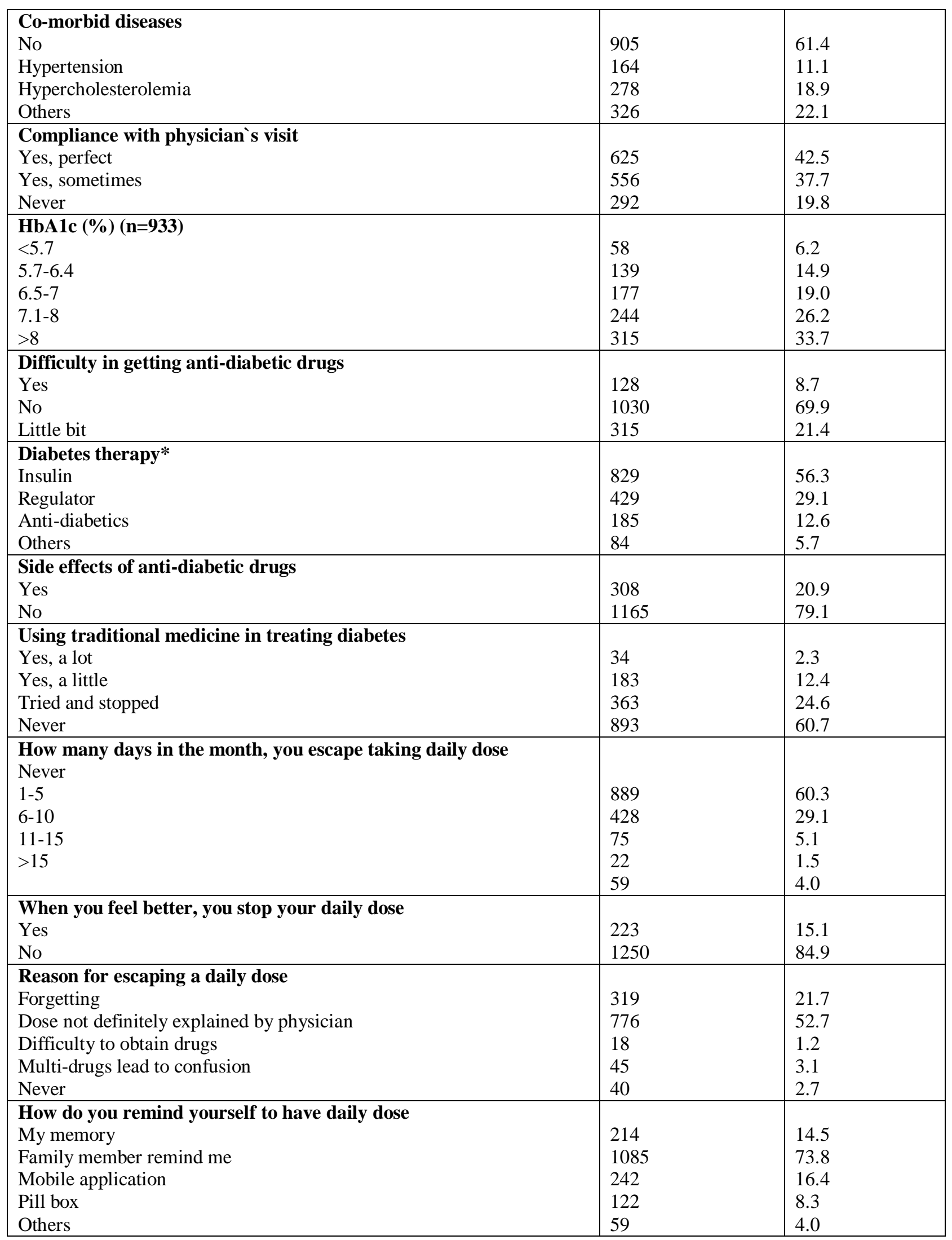

* Sum exceeds $100 \%$ 
Patients who stopped treatment when felt well represented $15.1 \%$ of the participants. The commonest reported reasons for escaping a daily dose of anti-diabetic drugs were being not definitely explained by physician (52.7\%) and forgetting $(21.7 \%)$. Most of the participants reported being reminded by family members to have the drugs.

The most frequent reported sources of patient`s information regarding diabetes were physicians (69.6\%) and internet $(59.9 \%)$ as illustrated in figure 1.

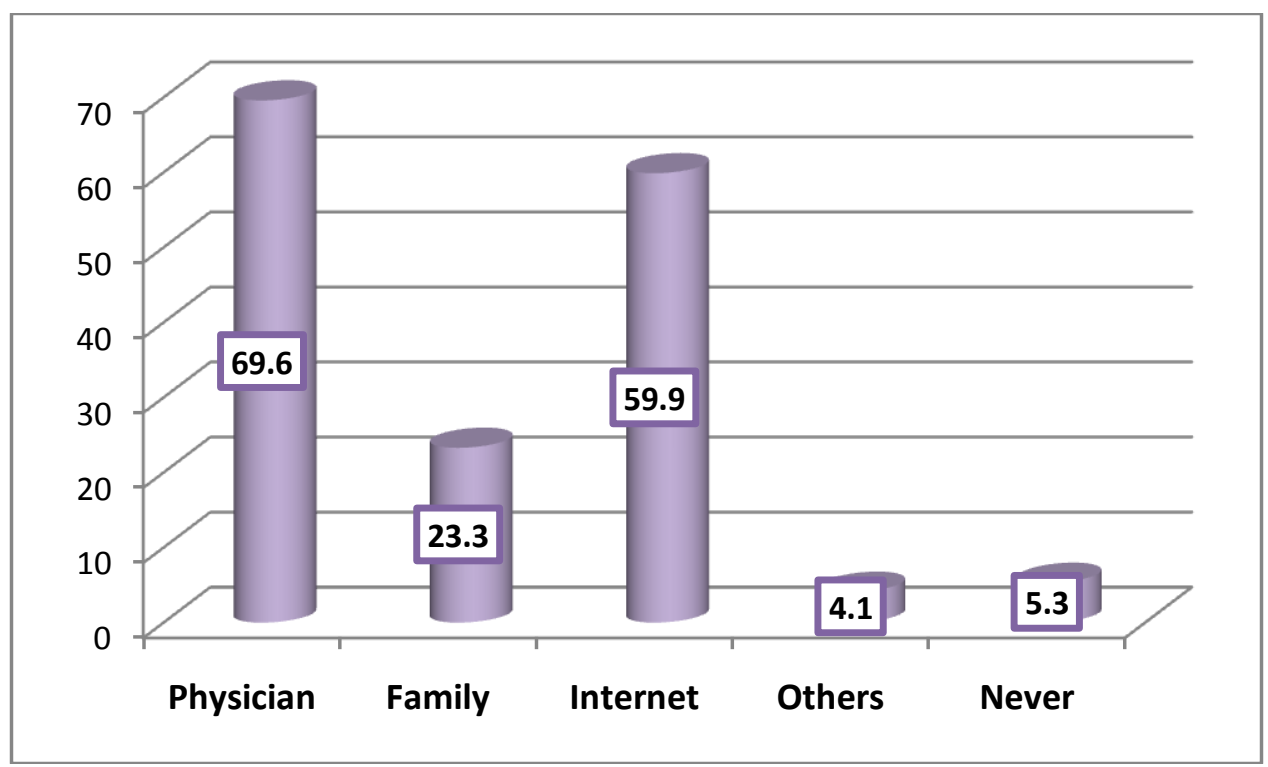

Figure 1:- Source of information regarding diabetes.

Table 3 presents the determinants of none-compliance to anti-diabetic medications. Regarding patient's age, the highest rate of non-compliance was reported among patients aged 18-25 years (51.6\%) whereas the lowest rate was reported among those aged over 60 years $(23.5 \%)$, $\mathrm{p}<0.001$.Regarding educational level, the highest rate of noncompliance was observed among secondary school graduates $(49.1 \%)$ whereas the lowest rate was reported among primary school graduated $(20.2 \%), \mathrm{p}<0.001$. Type 2 diabetic patients were more likely to be non-compliant than type 1 diabetic patients ( $42.6 \%$ versus $35.2 \%$ ), $\mathrm{p}=0.004$. Regarding age at diabetes diagnosis, the highest rate of non-compliance was reported among patients whose age at onset ranged between 18 and 25 years $(51.2 \%)$ whereas the lowest rate was observed among those whose age at diagnosis ranged between $41-60$ years $(32.3 \%), \mathrm{p}<0.001$. Diabetic patients with co-morbid diseases were less likely to be not compliant to anti-diabetic therapy compared to those without such diseases (36.8\% versus $41.4 \%), \mathrm{p}=0.043$. Patients who perfectly compliant with physicians` visits were more likely to be less non-compliant with anti-diabetic drugs compared to those who never being compliant with physicians` visit $(27.4 \%$ versus $52.1 \%), \mathrm{p}<0.001$. Patients treated with anti-diabetics had higher significant rate of non-compliance with drugs compared to those treated with insulin $(49.2 \%$ versus $35.6 \%)$, $\mathrm{p}=0.003$. Patients who are using traditional medicine a lot treated had higher significant rate of non-compliance with drugs compared to those tried them and then stopped (52.9\% versus $37.7 \%), \mathrm{p}=0.037$. The highest non-compliant rate was reported among patients whose source of information about diabetes was the family $(64.9 \%)$ whereas the lowest rate of non-compliance was reported among patients with source of information about diabetes other than physicians, family and internet (28.6\%). The difference was statistically significant, $\mathrm{p}=0.006$.

Table 3:- Factors associated with non-compliance with diabetic management

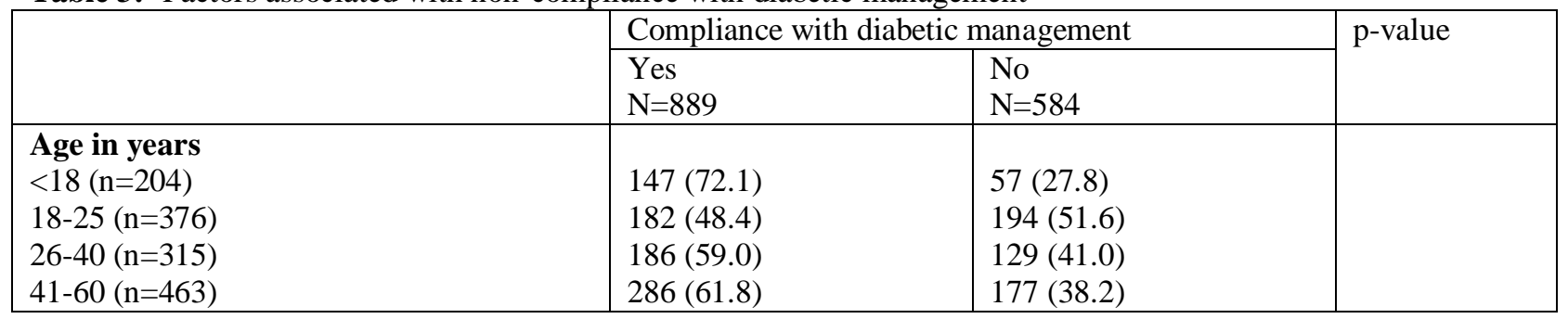




\begin{tabular}{|c|c|c|c|}
\hline$>60(n=115)$ & $88(76.5)$ & $27(23.5)$ & $<0.001$ \\
\hline $\begin{array}{l}\text { Gender } \\
\text { Male }(\mathrm{n}=797) \\
\text { Female }(\mathrm{n}=676)\end{array}$ & $\begin{array}{l}466(58.5) \\
423(62.6)\end{array}$ & $\begin{array}{l}331(41.5) \\
253(37.4)\end{array}$ & 0.109 \\
\hline $\begin{array}{l}\text { Marital status } \\
\text { Married }(n=768) \\
\text { Single }(n=634) \\
\text { Widowed }(n=44) \\
\text { Divorced }(n=27) \\
\end{array}$ & $\begin{array}{l}483(62.9) \\
366(57.7) \\
25(56.8) \\
15(55.6)\end{array}$ & $\begin{array}{l}285(37.1) \\
268(42.3) \\
19(43.2) \\
12(44.4)\end{array}$ & 0.223 \\
\hline $\begin{array}{l}\text { Educational level } \\
\text { Illiterate }(\mathrm{n}=93) \\
\text { Primary school }(\mathrm{n}=168) \\
\text { Intermediate school }(\mathrm{n}=115) \\
\text { Secondary school }(\mathrm{n}=348) \\
\text { University }(\mathrm{n}=749)\end{array}$ & $\begin{array}{l}67(72.0) \\
134(79.8) \\
70(60.9) \\
177(50.9) \\
441(58.9) \\
\end{array}$ & $\begin{array}{l}26(28.0) \\
34(20.2) \\
45(39.1) \\
171(49.1) \\
308(41.1) \\
\end{array}$ & $<0.001$ \\
\hline $\begin{array}{l}\text { Type of diabetes } \\
\text { Type } 1(n=587) \\
\text { Type } 2(n=886)\end{array}$ & $\begin{array}{l}381(64.8) \\
508(57.4)\end{array}$ & $\begin{array}{l}207(35.2) \\
377(42.6)\end{array}$ & 0.004 \\
\hline $\begin{array}{l}\text { Age at diagnosis } \\
<18(\mathrm{n}=536) \\
18-25(\mathrm{n}=205) \\
26-40(\mathrm{n}=399) \\
41-60(\mathrm{n}=313) \\
>60(\mathrm{n}=20)\end{array}$ & $\begin{array}{l}342(63.6) \\
99(48.8) \\
223(55.9) \\
212(67.7) \\
13(65.0)\end{array}$ & $\begin{array}{l}196(36.4) \\
104(51.2) \\
176(44.1) \\
101(32.3) \\
7(35.0)\end{array}$ & $<0.001$ \\
\hline $\begin{array}{l}\text { Co-morbid diseases } \\
\text { No }(n=905) \\
\text { Yes }(n=568)\end{array}$ & $\begin{array}{l}530(58.6) \\
359(63.2)\end{array}$ & $\begin{array}{l}375(41.4) \\
209(36.8)\end{array}$ & 0.043 \\
\hline $\begin{array}{l}\text { Compliance with physician`s visit } \\
\text { Yes, perfect }(\mathrm{n}=625) \\
\text { Yes, sometimes }(\mathrm{n}=556) \\
\text { Never }(\mathrm{n}=292)\end{array}$ & $\begin{array}{l}454(72.6) \\
295(\mathrm{n}=53.1) \\
140(47.9)\end{array}$ & $\begin{array}{l}171(27.4) \\
261(46.9) \\
152(52.1)\end{array}$ & $<0.001$ \\
\hline $\begin{array}{l}\text { HbA1c }(\%)(n=933) \\
<5.7(n=58) \\
5.7-6.4(n=139) \\
6.5-7(n=177) \\
7.1-8(n=244) \\
>8(n=315)\end{array}$ & $\begin{array}{l}34(58.6) \\
84(60.4) \\
114(64.4) \\
159(65.2) \\
183(58.1)\end{array}$ & $\begin{array}{l}24(41.4) \\
55(39.6) \\
63(35.6) \\
85(34.8) \\
132(41.9)\end{array}$ & 0.430 \\
\hline $\begin{array}{l}\text { Difficulty in getting anti-diabetic drugs } \\
\text { Yes }(n=128) \\
\text { No }(n=1030) \\
\text { Little bit }(n=315)\end{array}$ & $\begin{array}{l}75(58.6) \\
635(61.7) \\
179(56.8)\end{array}$ & $\begin{array}{l}53(41.4) \\
395(38.3) \\
136(43.2)\end{array}$ & 0.382 \\
\hline $\begin{array}{l}\text { Diabetes therapy* } \\
\text { Insulin }(\mathrm{n}=651) \\
\text { Regulator }(\mathrm{n}=266) \\
\text { Anti-diabetics }(\mathrm{n}=118) \\
\text { Others }(\mathrm{n}=70 \\
\text { More than one drug }(\mathrm{n}=368)\end{array}$ & $\begin{array}{l}419(64.4) \\
140(52.6) \\
60(50.8) \\
45(64.3) \\
225(61.1) \\
\end{array}$ & $\begin{array}{l}232(35.6) \\
126(47.4) \\
58(49.2) \\
25(35.7) \\
143(38.9) \\
\end{array}$ & 0.003 \\
\hline $\begin{array}{l}\text { Side effects of anti-diabetic drugs } \\
\text { Yes }(n=308) \\
\text { No }(n=1165)\end{array}$ & $\begin{array}{l}174(56.5) \\
715(61.4)\end{array}$ & $\begin{array}{l}134(43.5) \\
450(38.6)\end{array}$ & 0.119 \\
\hline $\begin{array}{l}\text { Using traditional medicine in treating } \\
\text { diabetes }\end{array}$ & & & \\
\hline
\end{tabular}




\begin{tabular}{|l|l|l|l|}
\hline Yes, a lot $(\mathrm{n}=34)$ & $16(47.1)$ & $18(52.9)$ & $87(47.5)$ \\
Yes, a little $(\mathrm{n}=183)$ & $96(52.5)$ & $137(37.7)$ & \\
Tried and stopped $(\mathrm{n}=363)$ & $226(62.3)$ & $342(38.3)$ & \\
Never $(\mathrm{n}=893)$ & $551(61.7)$ & $123(35.9)$ & \\
\hline Source of information & & $23(64.9)$ & \\
Physician $(\mathrm{n}=343)$ & $220(64.1)$ & $128(49.0)$ & \\
Family $(\mathrm{n}=49)$ & $26(53.1)$ & $6(28.6)$ & \\
Internet $(\mathrm{n}=261)$ & $133(51.0)$ & $269(37.3)$ & \\
Others $(\mathrm{n}=21)$ & $15(71.4)$ & $35(44.9)$ & \\
More than one source $(\mathrm{n}=721)$ & $452(62.7)$ & $43(55.1)$ & \\
Never $(\mathrm{n}=78)$ & & \\
\hline
\end{tabular}

\section{Discussion:-}

In recent years, there are a lot of studies showing increasing numbers of complication in diabetic patient in the world include Saudi population. ${ }^{17}$ for that reason, this study was carried out to explore the most common cause or reasons that influence and affecting the complication. Literature review of number of researches which talked this felid revealed that there was a lot of reasons; one of them is compliance with diabetic medication and how it was highly affect the complication rate.

In this study, compliance with anti diabetic medication was $60.3 \%$. In another study carried out in Uganda, ${ }^{14}$ a compliance rate of $83.3 \%$ has been reported. Kamel et al., (1999) ${ }^{18}$ reported that more than three quarters (78.3\%) of the studied diabetic patients adhered well to the medical treatment prescribed. Also, a rate of $78.3 \%$ had been observed in another study conducted in Alexandria, Egypt (1997) by Shama. ${ }^{19}$ In another study conducted in Ismailia city, Egypt (2003), ${ }^{20}$ it was concluded that $89 \%$ of the diabetic patients have never forgot taking their medications or have forgot to take their medications sometimes. In India, a compliance rate of $61.1 \%$ has been reported. ${ }^{21}$ In another Indian study, a rate of poor compliance of $74 \%$ has been reported. ${ }^{22}$ In a recently conducted study in Saudi Arabia, the overall prevalence of therapeutic non-compliance of the participants was $67.9 \% .{ }^{16}$ The apparent difference between the present study and other studies could be attributed to the fact that in this study, compliance was considered as never forget taking anti-diabetic medications while in other studies compliance was defined as taking at least $80 \%$ of daily anti-diabetic dose and/or differences in health care settings and socio economic status of the patients.

In the present study, the rate of type 1 diabetes was high compared to other figures reported worldwide and this is due to the fact that we included only those who had online access and majority of them were younger in age where type 1 diabetes prevail.

In our study, moderate educated patients were more likely to be non-compliant. In another Saudi study, ${ }^{16}$ higher educational levels of patients were found to be significantly associated with a higher compliance rate of the patients.. Another study have found the same results, ${ }^{23}$ while some studies have found no such association. ${ }^{24} \mathrm{~A}$ study conducted in the UK has shown that patients with a lower level of education have better compliance. ${ }^{25}$ It may be presumed that patients with a lower educational level may have more trust in the physician's advice. However, these results show that education may not be a good predictor of compliance with anti-diabetic medications.

Never compliance with physicians` visits was an important factor in non-compliance in our study. This could be due to the forgetfulness. Forgetfulness has been widely published as an important cause of irregularity of follow-up. ${ }^{26,27}$

The current study revealed that having information about diabetes from family was associated with higher rate of non-compliance compared to having such information from physicians or internet. The same has been reported in other similar studies. ${ }^{16,21,22}$

Patient physician relationship in this study has emerged as an important factor affecting patients' compliance. The most frequent mentioned reason for escaping medication was having inadequate information on anti-diabetic drugs from physicians. Those patients who did not get adequate information on dosage and side effects of the medicine, were more non-compliant. Numerous researches involving various diseases have evaluated the effect of the patientphysician relationship on patients' compliance, and has found it to be another strong factor in favour of patient compliance. ${ }^{27-29}$ Compliance to treatment advice was good when the physicians were supportive, supplied vital information, and listened patiently to patients. ${ }^{30}$ 
In the present study, nearly a fourth of the respondents reported having difficulty either totally or partially in getting one of the drugs in their regimen from the hospitals. However this was not significantly associated with noncompliance. Other studies have reported anti diabetic drugs stock-outs as a major constraint in managing diabetes. ${ }^{31-}$ 34

In the current study, type 2 diabetic patients, younger aged patients and those who were at younger age at diagnosis were more likely to report non-compliance with anti-diabetic therapy. The same has been documented by others. ${ }^{16}$, 21

Traditional medicine was used by a considerable proportion of patients in this study. The same had been reported by others. 14, 35-37

In the current study, we depend on self-rating of patient's compliance which usually overestimate patients Compliance levels. ${ }^{38}$

Conclusively, rate of non-compliance with anti-diabetic medication among Saudi diabetes is high and significantly associated with young age, younger age at diagnosis, moderate educational level, type 2 diabetes, absence of comorbid diseases, never compliance with physicians' visits, treatment by anti-diabetics, use of traditional medicine and having information about diabetes from the family.

Among important limitations of this study is the use of self reports as they might be subjective and may overestimate patients compliance rate. However, the assessments for compliance using self reports may make patients feel comfortable in telling the truth and may probably facilitate the identification of poor compliance. Online approach for recruiting patients affects definitely the representativeness and generalizability of results. However, this stud highlights the high non-compliance rate which consequently impacts the complication rate.

\section{References:-}

1. WHO. Global report on diabetes. 2016 available at: http://apps.who.int/iris/ bitstream/10665/204871/1/9789241565257_eng.pdf

2. García-Pérez LE, Alvarez M, Dilla T, Gil-Guillén V, Orozco-Beltrán D. Adherence to therapies in patients with type 2 diabetes. Diabetes Ther. 2013 Dec;4(2):175-94.

3. Horton R. Chronic diseases: the case for urgent global action. Lancet. 2007; 370:1881-1882.

4. Alqurashi KA, Aljabri KS, Bokhari SA. Prevalence of diabetes mellitus in a Saudi community. Ann Saudi Med. 2011 Jan-Feb;31(1):19-23.

5. WHO: A report; Chronic Diseases - Poor compliance of Patients with drug treatment[online] [Last cited on 2010 Oct 02]Available from: http://www.bio-medicine.org/medicine-news/In-Chronic-Diseases---Poorcompliance-of-Patients -with-drug-treatment--2097-1

6. Jansiraninatarajan. Diabetic compliance: A qualitative study from the patient's perspective in developing countries. IOSR 2013;1(4):29-38

7. Alwakeel JS, Sulimani R, Al-Asaad H, Tarif N, Al Suwaida A, Al-Mohaya S, et at. Diabetes complications in 1952 type 2 diabetes mellitus patients managed in a single institution. Ann Saudi Med 2008; 28(4): 260-266

8. Elhadd TA, Al-Amoudi AA, Alzahrani AS. Epidemiology, clinical and complications profile of diabetes in Saudi Arabia: a review. Ann Saudi Med. 2007 Jul-Aug;27(4):241-50.

9. RA, Khalil KH, Al-Qahtani MAA. Diabetic retinopathy and the associated risk factors in diabetes type 2 patients in Abha, Saudi Arabia Journal of Family and Community Medicine 2016;23(1):18-24

10. International Diabetes Federation-Middle East and North America. Diabetes in Saudi Arabia, 2015. Available at: http://www.idf.org/membership/,ena/Saudi-arabia

11. Nada AA, Ahmed GE. Diabetes knowledge among self reported DIABETIC female teachers: Al-Khobar, Saudi Arabia. J Family and Community Med 2005;12(1):110-115.

12. Azab AS. Glycemic control among diabetic patients. Saudi Medical Journal 2001; 22 (5): 407-409.

13. Khattab M, Khader YS, Al-Khawaldeh A, Ajlouni K. Factors associated with poor glycemic control among patients with Type 2 diabetes. J Diabetes Complications. 2010; 24(2):84-89.

14. Bagonza J, Rutebemberwa E, Bazeyo W. Adherence to anti diabetic medication among patients with diabetes in eastern Uganda; a cross sectional study. BMC Health Serv Res. 2015 Apr 19;15:168.

15. Park KA, Kim JG, Kim BW, Kam S, Kim KY, Ha SW, et al. Factors that Affect Medication Adherence in Elderly Patients with Diabetes Mellitus. Korean Diabetes J. 2010;34(1):55-65. 
16. Khan AR, Al-Abdul Lateef $\mathrm{ZN}$, Al Aithan MA, Bu-Khamseen MA, Al Ibrahim I, Khan SA. Factors contributing to non-compliance among diabetics attending primary health centers in the Al Hasa district of Saudi Arabia. J Family Community Med. 2012;19(1):26-32.

17. Khan AR, Al-Abdul Lateef ZN, Fatima S, Al Yousuf SAA, Afghan SZK, Marghani S. Prevalence of Chronic Complication among Type 2 Diabetics Attending Primary Health Care Centers of Al Ahsa District of Saudi Arabia: A Cross Sectional Survey. Global Journal of Health Science 2014; 6(4): 245-253

18. Kamel NM, Badawy YA, El-Zeiny NA, Merdan IA. Socio-demographic determinants of management behavior of diabetic patients, part I: behavior of patients in relation to management of their disease. EMHJ 1999; 5(5):967-973.

19. Shama ME, Study pattern of compliance behavior of diabetic patients attending diabetic health insurance clinics in Alexandria [thesis] University of Alexandria, Egypt, 1997.

20. Kamel MH, Ismail MA, El-Deib AR, Khattab MS. Predictors of self-care behavior in adults with type 2 diabetes mellitus in Abu Khalifa village, Ismailia, Egypt. Suez Canal Univ Med J. 2003; 6(2)-185-195.

21. Park KA, Kim JG, Kim BW, Kam S, Kim KY, Ha SW, et al. Factors that affect medication adherence in elderly patients with diabetes mellitus. Korean Diabetes J. 2010;34(1):55-65.

22. Sankar UV, Lipska K, Mini GK, Sarma PS, Thankappan KR. The adherence to medications in diabetic patients in rural Kerala. India: Asia-Pacific Journal of Public Health; 2013.

23. Ghods AJ, Nasrollahzadeh D. Noncompliance with Immunosuppressive Medications after Renal Transplantation. Tissue Antigens. 2002;60:553.

24. Spikmans FJ, Brug J, Doven MM, Kruizenga HM, Hofsteenge GH, van Bokhorst-van der Schueren MA. Why do diabetic patients not attend appointments with their dietitian? J Human Nutr Diet.2003;16:151-8.

25. Senior V, Marteau TM, Weinman J. Self-reported adherence to cholesterol-lowering medication in patients with familial hypercholesterolaemia: The role of illness perceptions. J Cardiovasc Drugs Ther.2004;18:475-81

26. Lee VW, Leung PY. Glycemic control and medication compliance in diabetic patients in a pharmacist-managed clinic in Hong Kong. Am J Health Syst Pharm. 2003;60:2593-6.

27. Hernández-Ronquillo L, Téllez-Zenteno JF, Garduño-Espinosa J, González-Acevez E. Factors associated with therapy noncompliance in type-2 diabetes patients. Salud Publica Mex. 2003;45:191-7.

28. Cummings KM, Kirscht JP, Binder LR, Godley AJ. Determinants of drug treatment maintenance among hypertensive persons in inner city Detroit. Public Health Rep. 1982;97:99-106.

29. Kim YS, Sunwoo S, Lee HR, Lee KM, Park YW, Shin HC, et al. Determinants of non-compliance with lipidlowering therapy in hyperlipidemic patients. Pharmacoepidemiol Drug Saf. 2002;11:593-600.

30. Lawson VL, Lyne PA, Harvey JN, Bundy CE. Understanding why people with type 1 diabetes do not attend for specialist advice: A qualitative analysis of the views of people with insulin-dependent diabetes who do not attend diabetes clinic. J Health Psychol. 2005;10:409-23.

31. Gill G. Diabetes in Africa - Puzzles and challenges. Indian J Endocrinol Metab. 2014;18(3):249-51.

32. Beran D, Yudkin JS. Diabetes care in sub-Saharan Africa. Lancet. 2006;368(9548):1689-95.

33. Hogerzeil HV, Liberman J, Wirtz VJ, Kishore SP, Selvaraj S, Kiddell-Monroe R, et al. Promotion of access to essential medicines for non-communicable diseases: practical implications of the UN political declaration. Lancet. 2013;381(9867):680-9.

34. Goudge J, Gilson L, Russell S, Gumede T, Mills A. Affordability, availability and acceptability barriers to health care for the chronically ill: longitudinal case studies from South Africa. BMC Health Serv Res. 2009;9:75.

35. Rutebemberwa E, Lubega M, Katureebe SK, Oundo A, Kiweewa F, Mukanga D. Use of traditional medicine for the treatment of diabetes in Eastern Uganda: a qualitative exploration of reasons for choice. BMC Int Health Hum Rights. 2013;13:1

36. Aikins A-G. Healer shopping in Africa: new evidence from rural-urban qualitative study of Ghanaian diabetes experiences. BMJ. 2005;331(7519):737.

37. Matheka DM, Demaio AR. Complementary and alternative medicine use among diabetic patients in Africa: a Kenyan perspective. Pan Afr Med J. 2013;15:110.

38. Kalyango JN, Owino E, Nambuya AP. Non-adherence to diabetes treatment at Mulago Hospital in Uganda: prevalence and associated factors. Afr Health Sci. 2008;8(2):67-73. 